\title{
Rapid Assessment of Covid 19 Pandemic on Uptake of Routine Immunizations amongst Children in a Fixed Site in Yaoundé, Cameroon
}

\section{Anne Esther Njom Nlend ${ }^{1 *}$, Nga Motaze Annie ${ }^{1}$ and Arsene Brunelle Sandie $^{2}$}

${ }^{1}$ Essos Hospital Centre, National Social Insurance Fund Hospital, Yaoundé, Cameroon

${ }^{2}$ Panafrican University, Nairobi, Kenya

*Corresponding Author: Anne Esther Njom Nlend, Associate Professor of

Paediatrics, Essos Hospital Centre, National Social Insurance Fund Hospital,

Yaoundé, Cameroon.
Received: October 29, 2020

Published: November 30, 2020

(C) All rights are reserved by Anne Esther

Njom Nlend., et al.

\begin{abstract}
Objective: To report on the tendency of immunizations uptake amongst infants in a fixed post of vaccinations, following the Covid 19 first case in Yaounde.

Method: This was a cross sectional study. Data were sourced from the pediatric unit registries of ESSOS Hospital Center (EHC). We compared absolute number of expanded immunization doses received over the same period in February to April 2019 and 2020 respectively The Statistical software R version 4.0.2 was used for all computations.

Results: A total of 168 and 148 babies were born in EHC during the month of February 2019 and 2020 respectively. The vaccinate rate decreased from April to May with rates in 2020 lower than in 2019 (54\% (80/148) vs 81\% (137/168), p < 0.001), which corresponds to pandemic period.

Conclusion: In this setting, without any reported stock outs of unit doses of routine immunization programme, a slightly decrease was observed in 2020, due to the COVID outbreak.
\end{abstract}

Keywords: Covid 19; Immunization; Children

Cameroon is recorded amongst the countries of Sub-Saharan Africa most affected numerically by the Covid pandemic [1]. Since the notification of the first case of infected person to SARS Cov 2 on the 6th March 2020 in Cameroon, mandated prevention using barriers methods, social distancing and stay at home messages were declared on the 18 March. In addition, specific messages were targeting health facilities notably: limitations of visitors to hospitalized patients, limitations of non-mandated consultations and prioritization of both medical and surgical emergencies. In regards to maternal and child health, the key messages of stay at home plus social distancing were displayed with respect of routine follow-up of maternal and child care. Specifically, the continuity of essential services of care for children was overemphasized. Despite communication using various channels, false messages were done. Those conflicting messages outlined the need to over space routine and essential visits at hospital in order to avoid the risk of contracting Covid disease in health facilities. Due to this context, we validated the perinatal guidelines on clinical management of mothers and their newborns in the Covid period. In addition, the national programme of immunization developed a guidelines for promotion and maintenance of routine immunization within this outbreak [2]. The key element of the strategy in site of EPI, included 1/organization 
of provision services though reception of 5 couples mothers and babies at a time in an allocated space ensuring social distinction of at least 1 meter around each participant, 2/adoption of barriers method by all the providers : ensuring availability of handwashing for all mothers and caregivers at the entrance of unit plus mask wearing. The weekly calendar of expanded immunization program remains in changed. This paper reports the tendency of immunizations uptake amongst infants in a fixed post of Expanded Program Immunization. Data were sourced from the pediatric unit registries of ESSOS Hospital Center (EHC), the total number of babies born at ESSOS Hospital Center during the month of February for 2019 and 2020 respectively were determined. Doses of vaccines considered: 1st dose/BCG/POLIO 0, 2nd and 3rd dose of combined hexavalent vaccine protecting babies against [diphtheria, tetanus, pertussis (whooping cough), poliomyelitis, Haemophilus influenza type B plus hepatitis B) + Pneumo 13 and Rotarix, followed by the 4th dose without rotavirus vaccine. The proportions of babies from the two cohorts 2019 and 2020, who got the 4 doses of vaccines were estimated by reporting the observed total number of each vaccine on the total number of babies born in February and May 2019 and 2020. The Statistical software R version 4.0.2 was used for all computations. Results are summarized in figure 1. A total of 168 and 148 babies were born in EHC during the month of February 2019 and 2020 respectively. All of them got their first vaccine, including the extra babies who were born in a different place than HEC, giving a vaccination rate(VR) in February of 121\% (203/168) and 135\% (200/148) respectively for 2019 and 2020. Overall, the VR was greater in 2020 than in 2019 for the months of February and March. However, we noticed a slight change from April and May with VR lower in 2020 compared to 2019 (54\% (80/148) vs 81\% (137/168), $\mathrm{p}<0.001)$, which corresponds to pandemic period. Though this observation if limited to a single site, it raises caution on the possible effect of the COVID 19 pandemic on uptake of doses of routine immunization. Our observations therefore could be concordant with those displayed by other teams $[3,4]$, thus urging to foster efforts in order to maintain the required coverage of immunization during the first year of life within this pandemic.

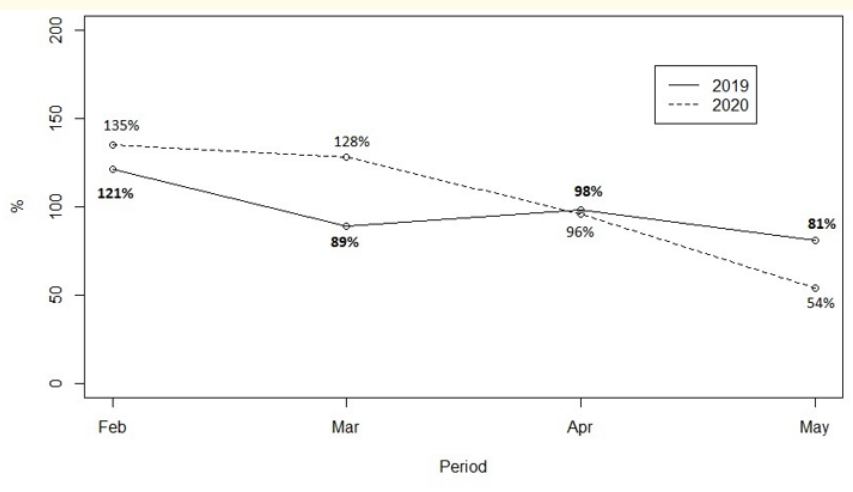

Figure 1: Vaccinate rate for 2019 and 2020 respectively during the months of February, March, April and May at Essos Hospital Center.

\section{Bibliography}

1. Covid -19. Situational Report. World health organization, regional office Africa (2020).

2. Ministry of Public health. Guidelines of immunizations within the COVID context (2020).

3. McDonald HI., et al. "Early impact of the coronavirus disease (COVID-19) pandemic and physical distancing measures on routine childhood vaccinations in England, January to April 2020". Euro Surveillance 25.19 (2020): 2000848.

4. Bramer CA., et al. "Decline in Child Vaccination Coverage During the COVID-19 Pandemic - Michigan Care Improvement Registry, May 2016-May 2020". Morbidity and Mortality Weekly Report 69.20 (2020): 630-631.

\section{Assets from publication with us}

- Prompt Acknowledgement after receiving the article

- Thorough Double blinded peer review

- Rapid Publication

- Issue of Publication Certificate

- High visibility of your Published work

Website: www.actascientific.com/

Submit Article: www.actascientific.com/submission.php

Email us: editor@actascientific.com

Contact us: +91 9182824667

Citation: Anne Esther Njom Nlend., et al. "Rapid Assessment of Covid 19 Pandemic on Uptake of Routine Immunizations amongst Children in a Fixed Site in Yaoundé, Cameroon”. Acta Scientific Paediatrics 3.12 (2020): 30-31. 